\title{
Preparation of porous carbon as ethylene adsorbent by pyrolysis of extraction waste Mangosteen rinds
}

\author{
Nur Indah Fajar Mukti ${ }^{\text {I, }}$, Imam Prasetyo ${ }^{2}$, Aswati Mindaryani ${ }^{2}$, and Shofwatunnida' Septarini ${ }^{I}$ \\ ${ }^{1}$ Department of Chemical engineering, Faculty of Industrial Technology, Universitas Islam Indonesia, Indonesia \\ ${ }^{2}$ Department of Chemical engineering, Faculty of Engineering, Universitas Gadjah Mada, Indonesia
}

\begin{abstract}
Mangosteen rind is an important source of natural antioxidants. Due to the growing interest in extracting this anti cancer substances from the mangosteen rind, the amount of this lignocellulosic residu has been generated significantly as byproduct. In this research, extraction-waste mangosteen rind (EMP) was used as alternative precusor for production of carbon-based adsorbent for ethylene removal. Steam was used as activating agent and the effect of carbonization time and temperature on the development of pore structure were examined. Pyrolysis process was carried out by heating the mangosteen rinds powder (180 $\mu \mathrm{m}-355$ $\mu \mathrm{m})$ from ambient temperature up to carbonization temperature of $848 \mathrm{~K}$ and kept for 3 hours then followed by heating up to $1123 \mathrm{~K}$ and kept for 15 minutes under flowing $\mathrm{N}_{2}$ and steam. This process was repeated for several pyrolysis temperature $(1053 \mathrm{~K}, 1073 \mathrm{~K}, 1083 \mathrm{~K}$ and $1103 \mathrm{~K})$ and carbonization time ( 0 hours, 1 hour, 2 hours, and 3,5 hours). The carbon obtained was characterized in terms of its pore structure and ethylene uptake capacity. The results show that porous carbon obtained from pyrolysis of extraction-waste mangosteen rind can be characterized as mesoporous carbon. The highest surface area of $1080 \mathrm{~m}^{2} / \mathrm{g}$ was obtained from pyrolysis of extraction-waste mangosteen rinds with carbonization time of 3.5 hours and pyrolysis temperature of $1123 \mathrm{~K}$. Furthermore, the mesopore portion and the specific surface area increased with the increasing carbonization time. From the ethylene uptake experiment, it was noted that the ethylene adsorption capacity of EMPC is $40.12 \mathrm{~cm}^{3} / \mathrm{g}$.
\end{abstract}

\section{Introduction}

Porous carbon with high surface area has been produced from a variety of carbonaceous materials. In practice, coal and lignocellulosic materials are often used as raw materials. The production of porous carbon from lignocellulosic material has been widely studied. There are the production of porous carbon from coconut shell, mangosteen rind, corn cob, bagasse, durian rind $[2,3,8]$. From the several previous studies, the mangosteen rinds has the potential as a raw material for the preparation of porous carbon with high surface area so that it can be used as an adsorbent with the large capacity $[6,8]$.

Mangosteen fruit (Garcinia mangostana L.) is a fruit immensely produced in Indonesia. Every part of the fruits containts an antioxidants, especially on the rind. Antioxidant compounds in the form of xanthones in mangosteen rind can be obtained through extraction process. Extraction process will extract a compound to obtain xanthones and will leave a residue in the form of mangosteen rind which the antioxidant compounds has been extracted. Because of the increasing demand of mangosteen rind extraction recently, it will also increase the mangosteen rind residue leftover from the extraction process. Because of the potential of the mangosteen rind residual waste, the research will conduct the utilization of waste as a new potential that can be used as raw material for producing porous carbon to obtain economic value. Porous carbon produced will be used as an ethylene adsorbent.

The pore structure of the porous carbon was highly depended on a raw materials and production methods. Activation process was a very important step in the preparation of porous carbon which aims to increase the porosity of the carbon produced. The increasing porosity of the carbon, the specific surface area of the carbon will increase. The activation methods were used among others by using physical activation through a partial gasification with $\mathrm{CO}_{2}$ and steam and chemical activation using chemicals such as $\mathrm{K}_{2} \mathrm{CO}_{3}, \mathrm{KOH}, \mathrm{ZnCl}_{2}$. Increased porosity with partial gasification consists of only one stage in which the pyrolysis beginning with carbonization process and proceed with partial gasification carried out in a single step [7]. While pyrolysis with the addition of chemicals was carried out in two steps. The first steps was the addition of chemicals and the next step was pyrolyzed the materials from ambient temperature to the desired temperature [1].

One of the methods in prolonging postharvest life of fruits is carried out by controlling ethylene concentration in the stored environments. It is necessary therefore to develop lower cost and more effective ethylene adsorption materials. This study was aimed to explore the feasibility of preparing ethylene adsorbent by pyrolysis of

\footnotetext{
* Corresponding author: nurindah_fm@uii.ac.id
} 
extraction waste mangosteen rinds under different carbonization conditions. The carbon obtained was characterized in terms of its pore structure and ethylene uptake capacity.

\section{Materials and methods}

\subsection{Material}

Manggosteen rinds powder $(180 \mu \mathrm{m}-355 \mu \mathrm{m})$ was obtained from Bina Agro Mandiri, Bantul, D.I. Yogyakarta. Nitrogen with a purity of $99.95 \%$ was used as an inert gas in the carbonization process, and to determine the $\mathrm{N}_{2}$ adsorption-desorption at $77 \mathrm{~K}$ was used $\mathrm{N}_{2}$ with ultra high purity (99.9995) as adsorbate. Ethylene with a purity of $99.9 \%$ was obtained from PT. Aneka Gas Industri as adsorbate.

\subsection{Experimental}

\subsubsection{Raw materials characterization}

Mangosteen rinds were characterized by lignocellulose content analysis using Chesson Method (Datta, 1981). Proximate analysis carried out by GB/T12496. Thermal Gravimetric Analysis (TGA) using Diamond TG/DTA Analyzer, PerkinElmer Instruments was carried out by heating a sample of $\pm 7 \mathrm{mg}$ from $303 \mathrm{~K}$ up to $1123 \mathrm{~K}$ with a heating rate of $5 \mathrm{~K} / \mathrm{min}$ under flowing nitrogen of 20 $\mathrm{mL} / \mathrm{min}$.

\subsubsection{Preparation of porous carbon}

Porous carbon for ethylene adsorbent in this study was prepared by pyrolysis of extraction waste mangosteen rinds (EMP). The carbon obtained from the former precursor is noted as EMPC. Furthermore EMPCT1 (1053 K), EMPCT2 (1073 K), EMPCT3 (1083 K), EMPCT4 $(1103 \mathrm{~K})$ and EMPCT5 $(1123 \mathrm{~K})$ were adjusted for variations in the temperature of pyrolysis and EMPCH1 (0 hour), EMPCH2 (1 hour), EMPCH3 (2 hours), EMPCH4 (3 hours) and EMPCH5 (3.5 hours) were adjusted for carbonization time. Precusors were pyrolized in furnace under flowing $\mathrm{N} 2$ from ambient temperature up to carbonization temperature of $848 \mathrm{~K}$ and kept for 3 hours, then followed by heating up to $1123 \mathrm{~K}$ and kept for 15 minutes under flowing N2 and steam. This process was repeated for several pyrolysis temperature $(1053 \mathrm{~K}, 1073$ $\mathrm{K}, 1083 \mathrm{~K}$ and $1103 \mathrm{~K}$ ) and carbonization time (0 hours, 1 hour, 2 hours, and 3.5 hours).

\subsubsection{Porous carbon characterization}

$\mathrm{N}_{2}$ adsorption-desorption obtained using NOVA 2000 adsorption analyzer (Quantachrome) at $77 \mathrm{~K}$. Spesific surface area $(\mathrm{S})$ calculated from isotherms data on the range of relative pressure $(\mathrm{P} / \mathrm{Po})$ between 0.05 to 0.30 . Total pore volume $(\mathrm{V})$ estimated from the amount of adsorbate adsorbed at $\mathrm{P} / \mathrm{Po}$ of 0.99 and a mesopore area (Smes), mesopore volume (Vmes) determined using $\alpha$ plot method. Pore size distribution studied using HorvathKawazoe method (HK) and Barret-Joyner-Haleda $\operatorname{method}(\mathrm{BJH})$.

\subsubsection{Ethylene Adsorption}

Ethylene Adsorption capacity test were carried out using the volumetric method at temperature of $303 \mathrm{~K}$. The ultra high vacuum adsorption measurement apartus rig was constructed by using Swagelok ${ }^{\circledR}$ VCR valve and fitting. The schematic diagram of adsorption system can be seen in Fig. 1. All carbon samples were first degassed at $423 \mathrm{~K}$ for 6 hours until the static pressure in the system was at least 1x10-2 Torr. The data obtained is presented as an adsorption isotherm curve. Ethylene adsorption analysis was began with ensuring all the valve in the closed state (V1, V2 and V3). To fill the loading cell, valve V1 was opened slowly to achieve the desired pressure and recorded as P1, then closed again. Furthermore, to make the process of adsorption, valve no. V2 was opened and observed a pressure decrease in the pressure gauge until the pressure in equilibrium obtained and recorded as $\mathrm{P} 2$. Adsorption equilibrium was indicated by stable pressure in the adsorption system. To proceed to the next equilibrium point, valve V2 was closed again and the steps were repeated until the maximum pressure that was able to operate $( \pm 1.2 \mathrm{~atm})$.

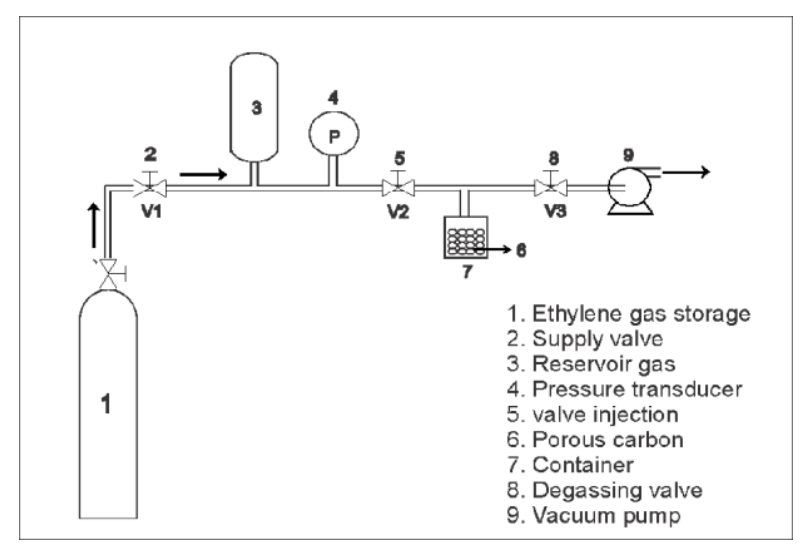

Fig. 1. Schematic Diagram of The Adsorpstion System by Static Volumetric

\section{Results and Discussion}

\subsection{Raw materials characterization}

\subsubsection{Proximate Analysis and Lignocellulose properties}

The results of lignocellulose analysis and proximate analysis are shown in Table 1. From the results show the composition of lignocellulosic of extraction waste mangosteen rind is mostly lignin of $48.52 \%$ and the proximate analysis shows that the maximum amount of carbon that can be obtained from mangosteen rind is $32.29 \%$. 
Table 1. Proximate Analysis and Lignocellulose Analysis

\begin{tabular}{|c|c|}
\hline \multicolumn{2}{|c|}{ Proximate Analysis } \\
\hline Component & Composition, $\%$ \\
\hline Water & 3.58 \\
\hline Ash & 1.85 \\
\hline Volatile matter & 62.28 \\
\hline Fixed carbon & 32.29 \\
\hline \multicolumn{2}{|c|}{ Lignocellulose Analysis } \\
\hline Component & Composition, $\%$ \\
\hline Cellulose & 26.22 \\
\hline Hemicellulose & 15.39 \\
\hline Lignin & 48.52 \\
\hline
\end{tabular}

\subsubsection{Thermal Gravimetric Analysis (TGA)}

TGA was carried out by heating a sample from $303 \mathrm{~K}$ up to $1123 \mathrm{~K}$ with a heating rate of $5 \mathrm{~K} / \mathrm{min}$ under flowing nitrogen. The results of TGA are shown in Fig. 2 . TGA analysis result shows the carbonization process of mangosteen rind was divided into several steps. The first step at temperatures $<150^{\circ} \mathrm{C}$, the weight loss due to evaporation of free and bound water. The second step at temperature of $200-375^{\circ} \mathrm{C}$, the weight loss due to the decomposition of cellulose and hemicellulose into condensable gases (methanol, tar and acetic acid) and uncondensable gases $\left(\mathrm{CO}_{2}, \mathrm{CH}_{4}\right.$, etc). Furthermore, at a temperature of $375-575^{\circ} \mathrm{C}$, the weight loss due to the decomposition of lignin. At temperatures $>575^{\circ} \mathrm{C}$, the weight loss was not significantly. The temperature of $575^{\circ} \mathrm{C}(848 \mathrm{~K})$ is taken as temperature carbonization.

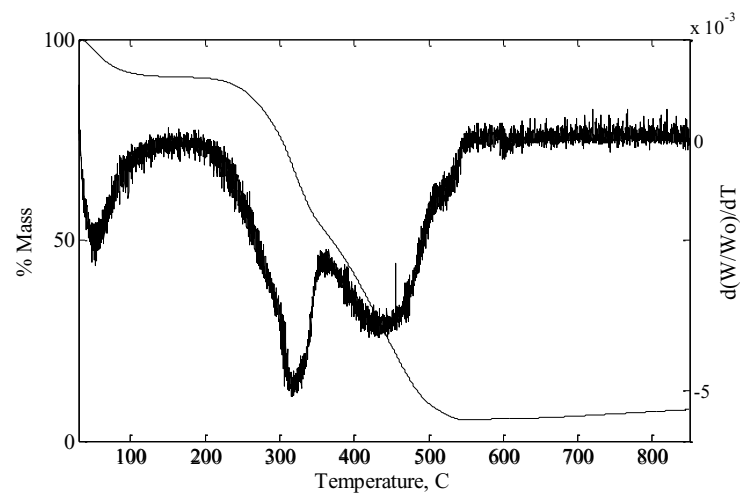

Fig. 2. TGA Curves of Mangosteen Rinds

\subsection{Porous carbon characterization}

\subsubsection{Effect of pyrolysis temperature}

Fig. 3(a) shows burn off number from porous carbon at various pyrolysis temperatures. Burn off can be used for quality criteria of carbon. If thermal degradation generates porous on material, when the burn off is high, it will increase the number of porous and internal surface area. Fig. 3(a) shows burn off number increasing by increase pyrolysis temperature.

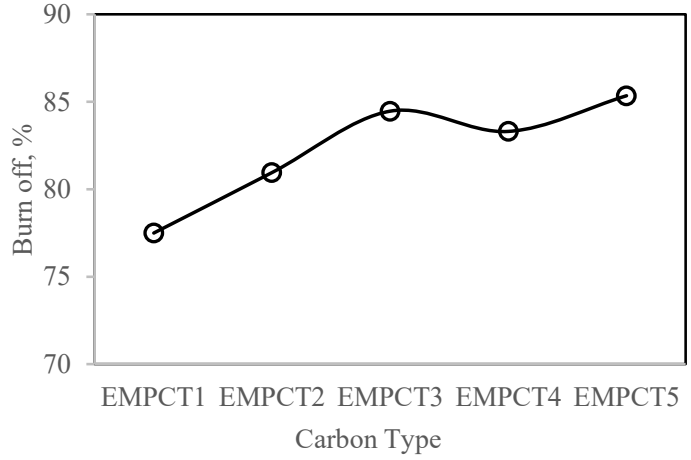

(a)

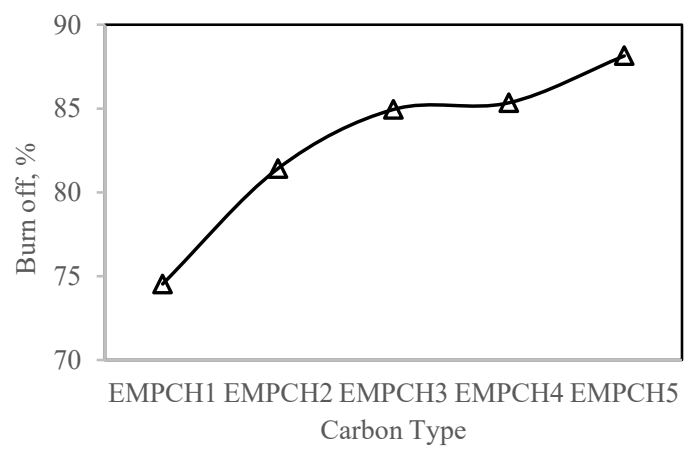

(b)

Fig 3. Burn off (a) EMPC at various $\mathrm{T}$ and $\mathrm{t}=3$ hours; (b) EMPC at various $\mathrm{t}$ and $\mathrm{T}=1123 \mathrm{~K}$

Fig. 3(b) shows number of burn off increasing when time of carbonization increased. Table 2 shows the pore structure of the carbon EMPC at various pyrolysis temperature. The Table 2 shows that the highest surface area is $1066.77 \mathrm{~m}^{2} / \mathrm{g}$ obtained from carbon obtained by pyrolysis of extraction waste mangosteen rinds up to 1123 $\mathrm{K}$ and carbonization time for 3 hours. Table 2 also shows that the specific surface area increased with the increasing pyrolysis temperature. Because of the formation of pore structure by $\mathrm{N}_{2}$ gas or superheated $\mathrm{H}_{2} \mathrm{O}$ will be growing at high temperature. Table 2 also provides information that the resulting pore volume also increased with higher pyrolysis temperature. The similar thing is seen for mesoporous volume. Wherein the resulting mesoporous volume increases with the increasing pyrolysis temperature.

Pore size distribution for carbon EMPC at various temperatures are shown in Fig. 4 (a). In Fig. 4(a) can be seen that for all carbon EMPCT1 until EMPCT5 have tendency of similar pore size distribution with the peak between 2-100 $\mathrm{nm}$ and have not any significant change. However, it can be seen that the pore size distribution is widened with increasing pyrolysis temperature. This is caused by the higher the pyrolysis temperature made micropore size widening thus increasing the amount of mesopore size. Therefore, it can be concluded that the portion of mesopore size also increase with the increasing temperature. 
Table 2. Characterization of EMPC at Various $\mathrm{T}$ and $\mathrm{t}=3 \mathrm{~h}$

\begin{tabular}{lccccccc}
\hline Sample & $\begin{array}{c}\mathrm{S}, \\
\mathrm{m}^{2} / \mathrm{g}\end{array}$ & $\begin{array}{c}\mathrm{S}_{\text {mes, }}, \\
\mathrm{m}^{2} / \mathrm{g}\end{array}$ & $\% \mathrm{~S}_{\text {mes }}$ & $\begin{array}{c}\mathrm{V}, \\
\mathrm{cm}^{3} / \mathrm{g}\end{array}$ & $\begin{array}{c}\mathrm{V}_{\text {mes }}, \\
\mathrm{cm}^{3} / \mathrm{g}\end{array}$ & $\% \mathrm{~V}_{\text {mes }}$ & $\begin{array}{c}\mathrm{D}_{\text {avg, }} \\
\mathrm{nm}\end{array}$ \\
\hline EMPCT1 & 657.61 & 565.96 & 86.06 & 1.115 & 0.835 & 74.89 & 6.78 \\
EMPCT2 & 839.31 & 527.32 & 62.83 & 1.051 & 0.749 & 71.27 & 6.62 \\
EMPCT3 & 979.55 & 543.35 & 55.47 & 1.172 & 0.969 & 82.68 & 4.78 \\
EMPCT4 & 1032.71 & 562.97 & 54.51 & 1.197 & 0.978 & 81.70 & 4.64 \\
EMPCT5 & 1066.77 & 603.61 & 56.58 & 1.276 & 1.069 & 83.78 & 4.79 \\
\hline
\end{tabular}

Table 3. Characterization of EMPC at Various $\mathrm{t}$ and $\mathrm{T}=1123 \mathrm{~K}$

\begin{tabular}{lccccccc}
\hline Sample & $\begin{array}{c}\mathrm{S}, \\
\mathrm{m}^{2} / \mathrm{g}\end{array}$ & $\begin{array}{c}\mathrm{S}_{\text {mes, }}, \\
\mathrm{m}^{2} / \mathrm{g}\end{array}$ & $\% \mathrm{~S}_{\text {mes }}$ & $\begin{array}{c}\mathrm{V}, \\
\mathrm{cm}^{3} / \mathrm{g}\end{array}$ & $\begin{array}{c}\mathrm{V}_{\text {mes }}, \\
\mathrm{cm}^{3} / \mathrm{g}\end{array}$ & $\% \mathrm{~V}_{\text {mes }}$ & $\begin{array}{c}\mathrm{D}_{\text {avg }}, \\
\mathrm{nm}\end{array}$ \\
\hline EMPCH1 & 697.89 & 527.32 & 75.56 & 1.051 & 0.749 & 71.27 & 6.03 \\
EMPCH2 & 951.12 & 556.70 & 58.53 & 1.201 & 1.030 & 85.76 & 5.05 \\
EMPCH3 & 1018.57 & 662.88 & 65.08 & 1.230 & 1.069 & 86.91 & 5.32 \\
EMPCH4 & 1066.77 & 603.61 & 56.58 & 1.276 & 1.069 & 83.78 & 4.79 \\
EMPCH5 & 1079.94 & 762.06 & 70.57 & 1.528 & 1.389 & 90.90 & 5.66 \\
\hline
\end{tabular}

\subsubsection{Effect of carbonization time}

Carbonization process of natural materials is affected by the decomposition process of the constituent material composition such as cellulose, hemicellulose and lignin. Therefore, if the cellulose, hemicellulose and lignin of the material decomposed perfectly, the quality of the carbon produced will be better characterized by the increasing on specific area of the carbon. To enhance the decomposition process of cellulose, hemicellulose and lignin from EMPC, the process on hold at the final temperature decomposition of lignin $(848 \mathrm{~K})$. Carbonization time variation was performed to determine the effect of the produced carbon character.

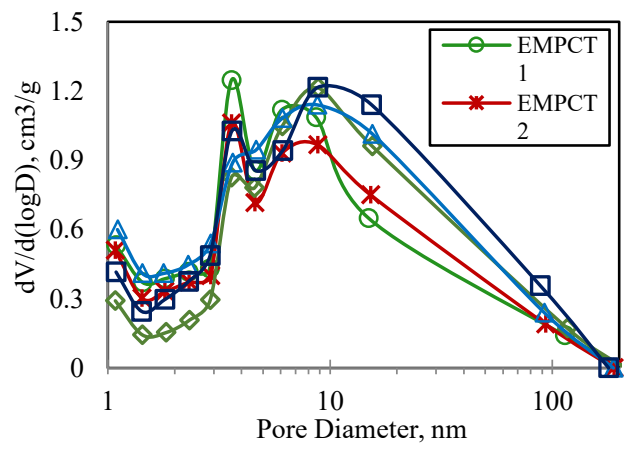

(a)

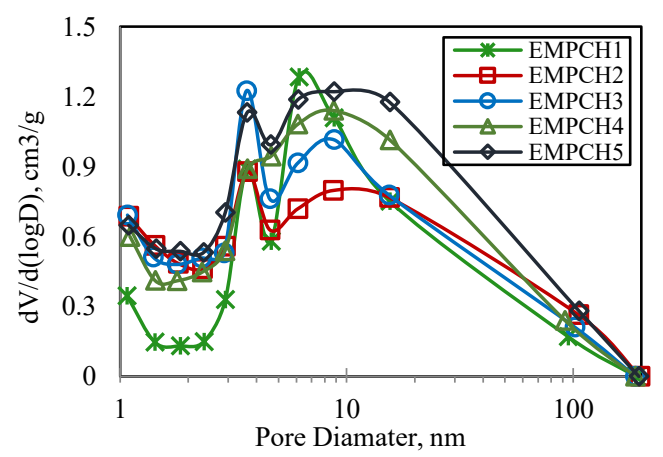

(b)

Fig 4. Pore Size Distribution BJH Method (a) EMPC at Various $\mathrm{T}$ and $\mathrm{t}=3$ Hours; (b) EMPC at Various $\mathrm{t}$ and $\mathrm{T}=1123 \mathrm{~K}$

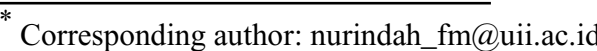

Table 3 shows the pore structure of the carbon EMPC at various carbonization time. The Table 3 provide information that the largest surface area is 1079.94 $\mathrm{m}^{2} /$ gram produced from carbon derived from extraction waste mangosteen rinds with carbonization time for 3.5 hours and a final pyrolysis temperature of $1123 \mathrm{~K}$. From these data, it is known that the specific surface area of the carbon produced will increase with the longer time of carbonization. It is due to the cellulose, hemicellulose and lignin from extraction waste mangosteen rinds will decompose perfectly so that the porosity of the carbon produced will also increase. Table 3 also informs that the longer carbonization time, the pore volume generated will also increase. Similarly, for mesoporous volume, the mesoporous volume will increase with the longer carbonization time. From these results, it can be stated that the structure of mesoporous carbon increase with the longer carbonization time.

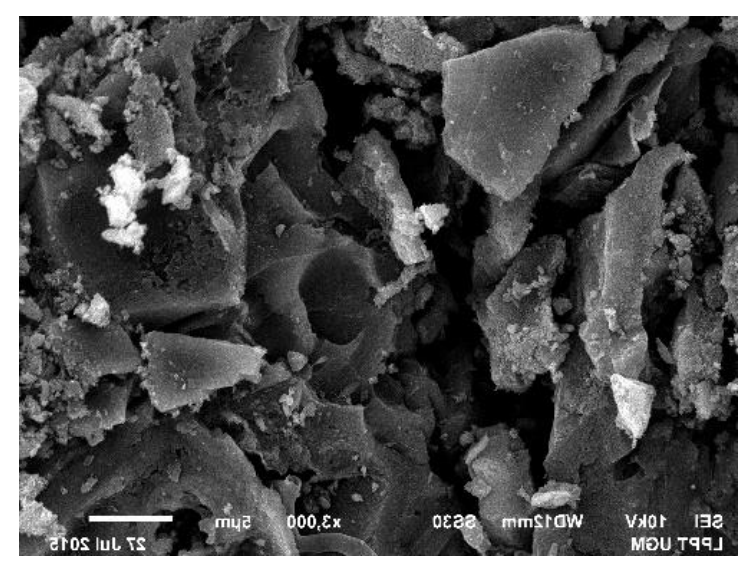

Fig 5. SEM Analysis for EMPC

Pore size distribution of carbon EMPC at various time can be seen in Fig. 4 (b). Fig. 4 (b) shows that all carbon EMPCH1 until EMPCH5 have the same pore size distribution with peaks between 2-100 nm. Pore size distribution was also widened with increasing carbonization time. This is caused by the higher the pyrolysis temperature made the micropore size widening thus it is increasing the amount of mesopore size. It can be concluded that the portion of mesopore size increase with the longer of carbonization time. 
The morphology of carbon analyzed by Scanning Electron Microscope Analysis (SEM). Fig. 5 shows the result of SEM analysis for EMPC.

\subsection{Ethylene Adsorption}

Calculation of the ethylene adsorption capacity carried out by volumetric methods. The results of adsorption experiments evaluated using adsorption isotherm models. Some adsorption isotherm models used are (Do, 1998):

Langmuir equation: $\mathrm{C}_{\mu}=\mathrm{C}_{\mu \mathrm{s}}\left(\frac{\mathrm{bP}}{1+\mathrm{bP}}\right)$

Freundlich equation: $\mathrm{C}_{\mu}=\mathrm{KP}{ }^{1 / \mathrm{n}}$

Unilan equation: $\mathrm{C}_{\mu}=\frac{\mathrm{C}_{\mu \mathrm{s}}}{2 \mathrm{~s}} \ln \left(\frac{1+\mathrm{be}^{\mathrm{s}} \mathrm{P}}{1+\mathrm{be}^{-\mathrm{s}} \mathrm{P}}\right)$

Sips equation: $C_{\mu}=C_{\mu s} \frac{(b P)^{1 / n}}{1+(b P)^{1 / n}}$

Toth equation: $C_{\mu}=C_{\mu s} \frac{b P}{\left[1+(b P)^{t}\right]^{1 / t}}$

Table 4. Parameter Value of Ethylene Adsorption Isotherm on $\mathrm{EMPC}$ at $\mathrm{T}=303 \mathrm{~K}$

\begin{tabular}{cc}
\hline Adsorption isotherm & Carbon Type \\
\cline { 2 - 2 } parameter & EMPC \\
\hline Langmuir & \\
C $\mu \mathrm{s}$ & 3.1808 \\
b & 1.1998 \\
Freundlich & \\
K & 1.6196 \\
n & 1.8361 \\
Toth & \\
C $\mu \mathrm{s}$ & 14.4335 \\
b & 0.5834 \\
t & 0.3805 \\
Sips & \\
C $\mu \mathrm{s}$ & 8.7359 \\
b & 0.1479 \\
n & 1.3929 \\
Unilan & \\
C $\mu \mathrm{s}$ & 3.1809 \\
b & 1.1998 \\
s & 0.0143 \\
\hline
\end{tabular}

The calculation result of the parameter values on various equilibrium equation can be seen in Table 4. The result of adsorption ethylene capacity for KSME carbon can be find on Fig 6. Fig 6 shows the ethylene adsorption capacity of EMPC is $1,792 \mathrm{mmol} / \mathrm{g}$ or $40.12 \mathrm{~cm}^{3} / \mathrm{g}$.

\section{Conclusions}

The feasibility of preparing carbon-based adsorbent for ethylene removal from extraction waste mangosteen rind were examined. In this study, porous carbon obtained from pyrolysis of extraction-waste mangosteen rind (EMPC) can be characterized as mesoporous carbon.
Carbon-based ethylene adsorbent with highest surface area of $1080 \mathrm{~m}^{2} / \mathrm{g}$ was obtained from pyrolysis of extraction waste mangosteen rinds with carbonization time of 3.5 hours and pyrolysis temperature of $1123 \mathrm{~K}$. Mesopore portion and the specific surface area increased with the increasing pyrolysis temperature. In addition, the mesopore portion and the specific surface area increased with the increasing carbonization time. The ethylene adsorption capacity of EMPC is $40.12 \mathrm{~cm}^{3} / \mathrm{g}$.

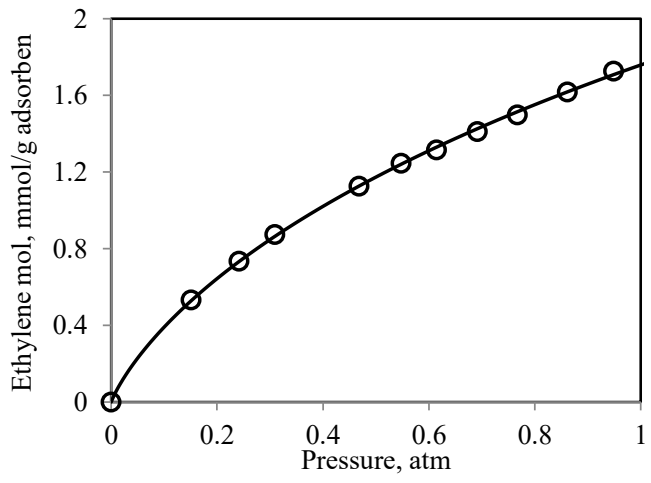

Fig 6. Ethylene Adsorption Isotherm on EMPC at $\mathrm{T}=303 \mathrm{~K}$

\section{References}

1. A. Ahmadpour, D.D. Do, The Preparation of Activated Carbon from Macadamia Nutshell by Chemical Activation. Carbon. 35, 12, 1723-1732 (1997).

2. A. Okhovat, A. Ahmadpour, F. Ahmadpour, Z.K. Yadegar, Pore Size Distribution Analysis of CoalBased Activated Carbons: Investigating the Effects of Activating Agent and Chemical Ratio. International Scholary Research Network, 2012, 1-10 (2012).

3. A.S. Bujang, Utilization of Durian Biomass of Biorenewable Aplications. Graduate Theses and Disertations, Iowa State University (2014).

4. D. D. Do, Adsorption analysis : Equilibria and Kinetics. Imperial College, London (1998).

5. E. P. Barret, L. G. Joyner, P. P. Halenda, The Determination of Pore Volume and Area Distributions in Porous Substances: I. Computations from Nitrogen Isotherms, 73, 373-380 (1951).

6. M.A. Ahmad, R. Alrozi, Optimization of Preparation Conditions for Mangosteen Peels Based Activated Carbon for The Removal of Remazol Brilliant Blue R Using Response Surface Methodology, Chem.Eng.Journal, 165, 883-890 (2010).

7. S.C. Kim, I.K. Hong, Pore Development of the Activated Carbon Prepared by Steam Activation Process. Journal of Industrial and Engineering Chemistry, 4, 3, 177-184 (1998).

8. Y. Chen, B.Huang, M. Huang, B. Cai, On the Preparation and Characterization of Activated Carbon from Mangosteen Shell, Journal of the Taiwan Institute of Chemical Engineers, 42, 837-842 (2011). 